\title{
El núcleo de las Prácticas Docentes: articulaciones, procesos de objetivación y ateneos
}

Mirta Espinosa ${ }^{(1)}$

\begin{abstract}
(1) Profesora Titular Ordinaria de Prácticas Docentes II. Coordinadora de Equipos de Prácticas de los profesorados de Educación Primaria,
\end{abstract}

Primaria Rural y de educación Especial. Facultad de Humanidades, Artes y Ciencias Sociales. Universidad Autónoma de Entre Ríos.

\section{Historización del campo en los Profesorados de Formación Docente rurales}

Nuestra Universidad es una de las que, junto a la UNCU, la Universidad de La Pampa y Tucumán, han pensado y organizado la formación docente de maestros como carrera de grado. Este dato tiene mucha relevancia porque los debates históricos sobre cuál es el nivel que debía/debe formar el docente de magisterio y por qué, dan cuenta de las tradiciones y los cambios en los imaginarios de época que muestran cómo en determinados momentos históricos los estudios para docencia primaria son propuestos como "unos seminarios y materias más que una formación secundaria" y en otros la demanda epocal es un alto grado de formación académico profesional". El archivo histórico de la Escuela Normal de Paraná da cuenta de esta historia en los preciosos "Informes del director" y otros documentos de época. Allí podemos ver cómo se formaron maestros en el nivel secundario en las épocas fundacionales, luego se terciarizó la formación en 1970 y como había tenido un breve pasaje por el nivel universitario allá por 1920, cuando en Paraná se fundó un anexo de la Universidad Nacional del Litoral. Las carreras de formación docente rural corrían con destinos similares a todas en estos vaivenes y tensiones. 
(1) Las pasadas décadas de empobrecimiento cultural tuvieron mucho que ver con esto. La femeinización sostenida de la carrera también tiene que ser tenida en cuenta en un país donde aún hoy tradiciones e imaginarios cuentan que "la docencia" es un segundo salario complementario en el hogar y además permite a las mujeres ejercer una profesión que libera parte de su día para trabajar en sus hogares. CTERA mostró en muchas de sus investigaciones (Silvia Vázquez, Iris Valle, Deolidia Martinez) la falacia de estos imaginarios y cómo más del 60\% de los docentes argentinos son, o el único, o el principal ingreso salarial. ¿Qué imaginarios se ponen en juego cuando se afirma que "siendo docente se trabaja mediodía y luego se tiene el resto del día libre?
Ochenta años después con la creación de la Universidad Autónoma la formación docente vuelve al nivel universitario en la Facultad de Humanidades. Este no es un dato menor. En términos político-pedagógicos porque implica toda una definición sobre cómo se concibe la educación de docentes primarios. Esta carrera ha sufrido el impacto innegable en las últimas décadas de la proletarización social de la profesión docente primaria en nuestro país. Las des-legitimaciones sociales que se cristalizan en imaginarios y prácticas serían tema de un seminario en sí mismo. Pero, es necesario explicitarlo al momento de plantear cómo entendemos que deben ser las prácticas en la formación docente, porque para nosotros está entrelazada con la producción de una formación magisterial que pueda colaborar en un proceso de restitución simbólica, de recuperación de respeto y la valoración social del magisterio y la educación básica en Argentina.

Es en este marco que queremos y podemos pensar las prácticas docentes y sus problemáticas en nuestras carreras. Necesitamos recurrir a la memoria cultural que nos muestra los debates y oscilaciones político-pedagógicas de las carreras de formación, no sólo por el nivel en que se situó a estos profesorados, sino por las sucesivas políticas estatales, curriculum, sus sujetos, sus problemas. La proletarización de la docencia es una problemática aún vigente en el sistema educativo y es también una realidad en los profesorados de formación docente de maestros, en otras palabras: pasa en las escuelas y pasa en los profesorados ${ }^{(1)}$.

Complejizando más aún esta trama, en el Profesorado situado en la histórica escuela rural Alberdi, otro debate transversalizó los anteriormente planteados. La misma idea de ruralidad fue puesta en debate en los grupos de discusión que trabajaban en la reformulación del plan de estudio, ya que en el profesorado se vivió y se participó intensamente en los días de las disputas por las políticas de redistribución de la renta agraria de algunos sectores rurales que tuvieron su punto más alto en el año 2008. En esos años se realizaron paneles, ciclos de debate y foros de cátedras.

En este profesorado circula una muletilla muy interesante para pensar este punto. Los alumnos suelen expresar "cuando vayamos al campo", poniendo en discurso una supuesta preparación en los primeros años de la carrera que tendría su culminación en la entrada al territorio de las prácti- 
cas en el tercer año, a un año de egresar de la carrera y casi seguramente de ingresar al sistema educativo por la alta demanda de cobertura de cargos que existe en nuestra provincia. Esto fue así hasta el año 2009 en que se implementa el nuevo Plan de estudios. ${ }^{(2)}$

Cambiar estos escenarios implicaba ir por la problematización de este sentido común tan sedimentado. "Cuando vayamos al campo". ¿Cuál campo? ¿Qué decimos cuando decimos campo? ¿Usted con quién está profe... con el campo o con el gobierno? Planteaban en el 2008. En estas encrucijadas de época se pensó la formación docente rural y se inició la transformación del plan de estudios. Recurrimos en este punto a algunos planteos construidos en plena crisis cuando aldeas, villas, escuelas rurales, alambrados se poblaron de banderas: "todos somos el campo", "defender el campo es defender la Patria", "estamos con el campo". Decíamos al respecto en ese momento y sostenemos hoy: muchos hilos se cruzan y se cruzan fuerte. El Estado, los agricultores, los hacendados, los pools de siembra, las federaciones agrícolas, la iglesia católica, la gente de la ciudad, el periodismo, los políticos... y también los que completan la escena, por su ausencia, los peones y trabajadores rurales y las grandes multinacionales que se mantienen en segunda línea calladas esperando el resultado de la pelea de los medianos y pequeños productores Monsanto, Cargill, Bunge, Dreyfus, por citar algunos de los grandes que monopolizan el envío de la cosecha argentina al exterior. Y cada grupo, cada sector se posiciona y "juega"(3) desde sus intereses.

Es imposible una comprensión cabal del problema si des-politizamos y des-historizamos el campo. Es necesario una mirada histórico-estructural, una mirada global que no olvide ninguno de los hilos de esta compleja trama social. Podemos decir con certeza con el sociólogo inglés Raymond Williams que no existe el campo. Lo que existe en un espacio social rural con muchos modos de vivir y de sentir el "campo". (4)

Esta idea es muy importante porque nos permite romper con la lógica y las imágenes folclóricas, cargadas de un exotismo fabricado acerca del campo, cuyo propósito ideológico es impedirnos pensar los contrastes y las desigualdades sociales del campo. El "campo" — parafraseamos a WiIliams - no nació con el capitalismo, pero es cierto que desde el siglo XIX hasta su configuración actual tiene sus marcas y sus huellas. Pensar el
(2) La Resolución № $1828 / 10$ del 29 de diciembre de 2010 del Rectorado de la Universidad aprueba el Plan de estudios del Profesorado de Educación Primaria de la Facultad de Humanidades, Artes y Ciencias Sociales, Paraná, Entre Ríos.

(3) En el sentido que da a este concepto Pierre Bourdieu "enjou" más que juego en sí define un sentido de juego que los sujetos despliegan en un determinado campo social, donde al modo de un juego, disputan sus intereses con sus capitales sociales. (4) Espinosa Mirta. Ponencia en la Jornada de apertura del ciclo Lectivo 2008: "Pensar la crisis del campo como apuesta para una pedagogía política. Ser Maestros Rurales hoy". Profesorado de Enseñanza Primaria con orientación rural Alberdi. FHA y Cs. S. 
(5) En rigor de verdad, los últimos quince años, las experiencias concretas de residencia han sido muy pocas, a pesar que la historia de la educación rural es rica en experiencias de modos plurales de residencias. modo de producción agrícola hoy implica pensar el modo de articulación de unas lógicas, unas modalidades de producción al mercado. Y entonces... las desigualdades del espacio rural (producto de la acumulación desigual del capitalismo) cobran materialidad social, es decir, podemos verlas en producciones y prácticas concretas. Sabemos que no vive y no produce igual un pequeño agricultor que tiene cien hectáreas que un pool de siembra que es dueño del setenta por ciento de las tierras de algún departamento de la provincia de Entre Ríos. En estos distintos y desiguales paisajes sociales somos o seremos maestros rurales.

Retomemos el planteo inicial; nuestros alumnos en realidad no van al campo, ese espacio social rural cargado de contrastes y desigualdades, un alto porcentaje de ellos vuelven al campo, porque son jóvenes del interior que vienen a la capital a estudiar. Este no es un dato menor, nos habla de sus subjetividades, de sus biografías escolares... también rurales, sus capitales culturales y también de qué tipo de entradas al territorio escolar y qué prácticas pedagógicas-docentes tuvimos y tenemos que pensar en el nuevo Plan de Estudios que se está implementando.

\section{La configuración de los trayectos de prácticas en núcleos}

Un relato de las prácticas docentes que realizamos implica entonces partir del marco referencial del nuevo Plan de Estudios iniciado en el 2009. En primer lugar este plan redefine sentidos y organización de los tradicionales espacios de cátedra planteados en trayectos, pero en el mismo movimiento de recuperarlos, los cuestiona en su naturaleza lineal al plantearlos ahora organizados en núcleos y poniendo como articulador central el núcleo de las prácticas docentes.

Todo trayecto invita a un recorrido, pero también implica un modo de recorrerlo. Nuestro viejo plan de estudios (2001) nos proponía itinerar una serie de saberes y prácticas en tercero y cuarto año de la carrera de magisterio rural que suponían la complejización gradual de conocimientos y prácticas docentes que culminaban con una residencia en las instituciones escolares del espacio social rural. ${ }^{(5)}$ 
Las cátedras que componían el trayecto portaban una tradición de trabajar autonomizadas unas de otras. A su vez, en una especie de juego de ondas concéntricas, el trayecto de prácticas ${ }^{(6)}$ mismo trabajaba sin vincularse a otros trayectos como el pedagógico o el de las didácticas disciplinares. Esta configuración era parte importante de los malestares institucionales, especialmente estudiantiles, ya que reclamaban la entrada a las escuelas coformadoras antes en la carrera, tanto como algunas articulaciones mínimas que potenciaran los logros y resguardaran la propuesta de yuxtaposiciones y vacancias. Teníamos en este punto un nudo central de análisis y desafíos. Retomemos la idea de núcleos. Esta modalidad organizativa en núcleos ${ }^{(7)}$ es uno de los cambios en el formato curricular de los nuevos diseños respecto de los anteriores como el citado Plan de 2001 y el de 1999. El nudo vertebrador en los núcleos se sitúa en el trabajo a partir de problema. Esto es la problematización de dos dimensiones fuertemente vinculadas:

Las prácticas docentes en sus dimensiones pedagógicas, curriculares, conocimientos contenidos, didácticas, estrategias, planificaciones, evaluaciones.

El contexto sociocultural e institucional de las prácticas pedagógicas-docentes.

Un modo de cristalizar y sostener esta idea fue la inclusión de un nuevo espacio de prácticas en el segundo año de la carrera, denominado "Contextos y prácticas educativas en el espacio social rural", donde los alumnos realizan sus primeros trabajos de conocimiento contextual e institucional. Las instituciones se consensúan con los equipos de investigación para que las experiencias en el territorio escolar puedan luego retomarse desde ambos campos.

La apuesta es a la potencialidad de los núcleos temáticos y problemáticos como posibilitadores de la integración tanto vertical como horizontal de las diferentes disciplinas académicas. El itinerario formativo cuyo núcleo central es la práctica docente, se va sustentando en otros núcleos que irán configurando ese sujeto docente en torno de posibilitarle la construcción de esquemas referencias teóricos y disciplinares amplios y específicos para el trabajo docente, al tiempo que contribuye desde estas dimensiones experienciales a los procesos identitarios profesorales.
(6) Al mismo tiempo, al interior de las cátedras la cotidianeidad escolar nos develaba las dificultades de los escenarios concretos.

Las prácticas que realizaban los/las estudiantes eran, generalmente, clases sueltas de 40 o 80 minutos, con contenidos fragmentados donde era muy difícil "leer" de un proceso/secuencia pedagógica concreto y por ende poder formular algunos criterios, indicadores aunque sea iniciales, sobre si hubo o cuánto hubo de apropiación de conocimientos de los alumnos de las escuelas coformadoras.

(7) "El núcleo posibilita pensar el curriculum como escenario donde se construye conocimiento, se cuestionan los valores dominantes $y$ se reinventan relaciones cognitivas, socioafectivas, intersubjetivamente y con los contextos. Las barreras existentes creadas por la cultura tradicional en materia curricular se apoyan en autonomías relativas de las disciplinas, impidiendo un tratamiento holístico y totalizador de la problemática estudiada; en respuesta a esta situación y en vistas de una concepción diferente, se propone abandonar el criterio asignaturista (materias aislada $\mathrm{y}$ atomizadas) y fortalecer el concepto de núcleo temático y problemático. Entendemos que éste constituye una unidad integradora, conjunto de conocimientos orientados a temáticas centrales para la formación, que posibilitan la definición de líneas de investigación en torno a la modificación de prácticas 
y de estrategias metodológicas que garanticen la síntesis creativa de teoría y práctica. Plan de estudios 2009. FHA y Cs.

(8) En la línea de lo planteado por Achilli (200o) en su texto Investigación y Formación docente. Sin desconocer que con lógicas diferentes la producción, creación, invención de conocimiento son propias de ambos campos.

(9) Las prácticas docentes constituyen un entramado dinámico configurado por saberes aportados por los otros núcleos, seminarios, cátedras que los estudiantes transitan, sujetos que participan en ellas, el contexto del espacio social rural donde se despliegan, conocimientos específicos de la formación docente en tanto práctica políticapedagógica y sociocultural. La idea de configuración en el sentido de Norbert Elías (1999) muestra su naturaleza relacional expresada en vínculos, interrelaciones e interdependencias.
Plantear la investigación y formación docente en relación implica el desafío de no confundir sus lógicas operantes, considerar que es el campo de la investigación quién produce los conocimientos y el de la formación quién trabaja y re-trabaja con los saberes sociales producidos. ${ }^{\left({ }^{(8)}\right.} \mathrm{Al}$ mismo tiempo, este posicionamiento conlleva una determinadas resoluciones metodológicas: la modalidad de relación que se asume es la articulación. "Nuestra idea es poner en juego las cátedras de investigación y de práctica articulándolas, es decir permitiendo en esta coyuntura que cada una haga su juego con la otra sin perder su identidad disciplinar. Es una tarea imprescindible en un presente que nos encuentra con un campo de las prácticas docentes que ha sufrido una profunda despolitización". La articulación se plantea a partir de dos ejes comunes: el conocimiento y las problemáticas que conforman la agenda de trabajo de cada campo.

El Núcleo central de las Prácticas docentes está constituido por la Práctica Docente, entendida como práctica pedagógica-relativa a los procesos de enseñar que comportan la relación docente-alumno-contenido mayormente en el escenario aula, práctica institucional y práctica política, eje organizador del currículo. Práctica docente y práctica pedagógica interactúan con prácticas de investigación a los fines de conjugar producción de conocimiento, reflexión sobre las prácticas y configuración del oficio magisterial. Siendo la investigación y las prácticas docentes sus dos campos vertebradores, es la naturaleza teórico-epistemológica de ambos lo que define la identidad de este espacio que, sin embargo, se configura plenamente en el anudamiento con todos los otros espacios de la propuesta curricular. ${ }^{(9)}$ En términos de propuestas concretas que posibilitaran algunas condiciones objetivas para llevar a cabo estas ideas, en este punto, uno de los cambios fue la incorporación de los equipos de las Didácticas Disciplinares III, en el trabajo al interior de los equipos de práctica en el tercer año de la carrera, en el segundo cuatrimestre.

Se comenzó un trabajo de reuniones por núcleos e internúcleos con vistas a completar y fortalecer aquellos equipos de cátedra que tenían vacancias docentes o de coordinación en el caso de las didácticas disciplinares. Al mismo tiempo, se concreta una agenda de reuniones de estudio y debate para abordar problemáticas que van surgiendo del trabajo concreto 
en y con las escuelas co-formadoras. A modo de ejemplo: la necesidad de acuerdos mínimos en contenidos curriculares, perspectivas, enfoques, modalidades de evaluación que va a trabajar cada cátedra en el núcleo de la enseñanza y el sociohistórico y los vínculos posibles con las prácticas. ${ }^{(10)}$ Es en el momento de la producción de prácticas pedagógicas concretas con las cuales se opera sobre la cotidianeidad escolar que los conflictos epistémicos por sí o traducidos en desacuerdos metodológicos o didácticos señalan que hay debates, acuerdos y puentes entre campos del conocimiento que necesitamos construir y sostener para construir una arena común.

La contextualización ${ }^{(11)}$ en el espacio social rural transversaliza los campos de conocimiento, así como también lo atraviesa el Ateneo entendido como espacio de objetivación de prácticas y de producción colectiva con instituciones co-formadoras. Tiene carácter teórico-metodológico en tanto significa que las prácticas investigativas y magisteriales se piensan y realizan en espacios sociales específicos y que su construcción pedagógica implica pensarlo como configuración constituida -constitutiva desde las múltiples dinámicas temporales y escalas espaciales que presentan los espacios rurales.

\section{El ateneo como un espacio colectivo de reflexión y sistematización de conocimientos}

Los Ateneos de las prácticas constituyen un espacio de intercambio para el análisis y reflexión de las experiencias de prácticas llevadas adelante desde los espacios específicos de cada cátedra que compone el trayecto, para luego ampliarse al trayecto e instituciones co-formadoras. Son un espacio colectivo de participación de estudiantes y docentes involucrados en las prácticas, abierto a toda la comunidad universitaria y de las escuelas co-formadoras. Cada ateneo pretende constituirse en lugar y tiempo de reflexión y la objetivación de las prácticas docentes-pedagógicas.

Estos dispositivos se organizan alrededor de dos ejes:
(10) Así planteadas las prácticas docentes descubren los entrecruzamientos plurales y complejos de sujetos sociales rurales, conocimientos y contexto, revelan su carácter procesual y la posibilidad infinita de figuras y figuraciones que se pueden construir/producir si se resisten las determinaciones a que las arrojan algunas tradiciones pedagógicas. Los encuadramientos teóricos y las construcciones metodológicas de las propuestas didácticopedagógicas son siempre provisionales.

(11) En el sentido de la conceptualización de Achilli (2000:15) en el texto Escuela y ciudad. Exploraciones de la vida urbana". 
(12) En este espacio se propone también el análisis y debate de la complejidad de las relaciones intergeneracionales que las prácticas conllevan, así como la recuperación de experiencias de prácticas investigativas y docentes para conformar un banco de memorias de prácticas magisteriales que sirva de insumo a los estudios de cátedras y los estudiantes

(13) Se solicita un número de tres problemáticas. (14) Problematizar quiere decir convertir cada tema en un problema, es cuestionar, interrogar, lo que está pasando y dimensionar sus consecuencias, cómo me afecta, cómo afecta a todos, de qué manera, cuándo, dónde, etc.". En el texto "El taller un espacio de producción compartida de saberes" de Nélida Landreani (1996), en Cuadernos de Capacitación Docente, Año I, $\mathrm{N}^{\circ}$.
(1) Procesos de objetivación de prácticas.

(1) Procesos colectivos de construcción de proyectos con las instituciones co-formadoras. ${ }^{(12)}$

El proceso de objetivación supone la problematización de las propuestas realizadas por los "practicantes" con el propósito que las interpelaciones permitan construir un relato/narrativa de sus experiencias pedagógicas y jerarquizar núcleos problemáticos claves $^{(13)}$ que serán insumos para trabajar colectivamente con los docentes de las prácticas y los de la institución co-formadora. La experiencia de prácticas de cada estudiante atraviesa este proceso y queda plasmada en una producción escrita.

La jerarquización de los núcleos claves tiene un sentido de ordenamiento que se realiza a partir de criterios de selección que den cuenta de su relevancia en la experiencia, citaremos cuatro: recurrencia/reiteración, significación, estrategia y vacancia. Definidos los núcleos se pasa a la instancia de problematización ${ }^{(14)}$ donde se trabaja sobre la interrogación a la experiencia de prácticas: qué se hizo, cómo se hizo, por qué de ese modo, qué otra propuestas se desestimaron, quiénes, en qué tiempos, para qué, dónde... es decir, una interpelación profunda que desentrame los hilos de este proceso, para luego finalmente realizar un trabajo de interpretación y conceptualización, de asignación de contenido teórico a la experiencia vivida a partir de bibliografía de las cátedras.

Finalmente, nos importa expresar que no se trata de renovar cambiando la configuración de un Plan, sino de producir una verdadera problematización de lo existente, para habilitar y autorizarnos nuevas ideas y propuestas. En este camino los riesgos de persistir en viejas prácticas con nuevos nombres, estará siempre latente. Es imprescindible la vigilancia epistémica sobre la idea de proceso. Dicho de otro modo, el trabajo con los planes y las nuevas propuestas implica si se permite una metáfora simple, que la película no cristalice en foto. Problematizar nuestro sentido común académico, cuestionar, reflexionar y trabajar colectivamente son herramientas fundamentales. Una vez más... no se trata de una disputa por las formas, aunque sabemos que son importantes. Como parte de la batalla cultural... la pelea en el campo de las prácticas docentes es por la adjudicación de sentidos. 


\section{Referencias bibliográficas}

Achilli, E.L. (1988). "Una interpretación desde los saberes del maestro". Cuadernos de antropología social, Año VI.

Bixio, C. Pogliotti, N. (2010). Imaginado la escuela posible. Un espacio social subjetivante. Rosario: Laborde.

(2000). Investigación y formación docente. Rosario: Laborde.

Dicker G. y Frigerio G. (2004). La transmisión en las sociedades, las instituciones y lo sujetos. Buenos Aires: Novedades Educativas.

Domján, G. y Patricia, A. Gabarini (2006). Residencias Docentes y prácticas tutoriales. Córdoba: Brujas. Escuela de Ciencias de la Educación. Facultad de Filosofía y Humanidades de la UNC.

Edelstein G. y Coria A. (1997). Imágenes e imaginación. Iniciación a la docencia. Buenos Aires: Kapeluz. Iglesias, L. (1995). La escuela rural unitaria. Fermentario para una pedagogía creadora. Buenos Aires: Editorial Magisterio del Río de la Plata.

Landreani, N. (1996). "El derecho de apropiación institucional" (o de cómo pagar el derecho de piso). Crítica Educativa, Año 1, T. 1. Buenos Aires.

(1998). El taller: un espacio compartido de producción de saberes, Año 1, No 1 . Facultad de Ciencias de la educación, UNER.

Morelli, S. (2010). "El currículum universitario entre la política y la academia, las demandas y las reformas". Rosario: Laborde.
Nicastro, S. y Greco, M.B. (2009). Entre trayectorias. Escenas y pensamientos en espacios de formación. (2006). Revisitar la mirada sobre la escuela. Exploraciones sobre lo ya sabido. Rosario: Homo Sapiens.

Pérez Fernández, M. (1998). La profesionalización del docente. Perfeccionamiento Investigación en el aula. Buenos Aires: Siglo XXI Editores. Introducción y Capítulos 1 y 2.

Rosbaco, Inés (2007). "El docente como representante del otro social: su función subjetivante". Revista de la escuela de Ciencias de la Educación, Año 3, № 2. Rosario: Laborde, p. 161.

Saleme, M. (1997). Decires. Córdoba: Narvaja Editores.

Skliar, C. (2002). ¿Y si el otro no estuviera allí? Notas para una pedagogía improbable de la diferencia. Buenos Aires: EMV-CTERA y Miño y Dávila Editores. Teriggi, F. (1999). Curriculum. Itinerarios para aprehender un territorio. Buenos Aires: Santillana.

Williams, R. (2001). El campo y la ciudad. Espacio del saber. Buenos Aires: Paidós.

Yuni, J.A. (2009). La formación docente. Complejidades y ausencias. Catamarca: Encuentro Grupo Editorial. Facultad de Humanidades de Catamarca. 